\title{
Mitteilungen der Schweizerischen Menopausengesellschaft / SMG
}

J. Gynäkol. Endokrinol. 2017 ·20:115

https://doi.org/10.1007/s41975-017-0003-3

(c) Springer-Verlag GmbH Austria 2017

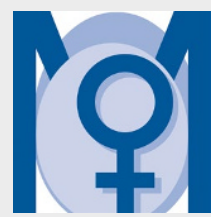

Präsidentin

Prof. Dr. med. Petra Stute (V.i. S. d. P.)

Administration SMG

Weißdornweg 17

D-35041 Marburg/Lahn

Tel.: +49 (0) 62093444

E-Mail: administration@meno-pause.ch
Liebe Kolleginnen und Kollegen!

Es gibt eine Neuerung in der SMG - anlässlich des Women's Health Congress 2018 wird erstmalig der SMG Wissenschaftspreis verliehen werden.

Hierbei wird besonderer Wert auf die wissenschaftliche Bearbeitung der Fragestellungen, die sich fachübergreifend aus zahlreichen Bereichen wie Diabetologie, Ernährungswissenschaft, Innere Medizin, Kardiologie, Onkologie, Ophthalmologie, Osteologie etc. ergeben, und auf die Förderung des interdisziplinären Dialogs gelegt.

Der SMG Wissenschaftspreis fordert junge wie auch erfahrene Wissenschaftler auf, ihre Arbeit einzureichen und sie einem fachkundigen Kreis vorzustellen, miteinander zu diskutieren und gegenseitig voneinander zu profitieren.

Wir würden uns sehr freuen, Sie begrüßen zu können, und freuen uns auf Ihre Einreichung!

Mit kollegialen Grüssen,

\section{Ihre Petra Stute}

Präsidentin Schweizerische

Menopausengesellschaft

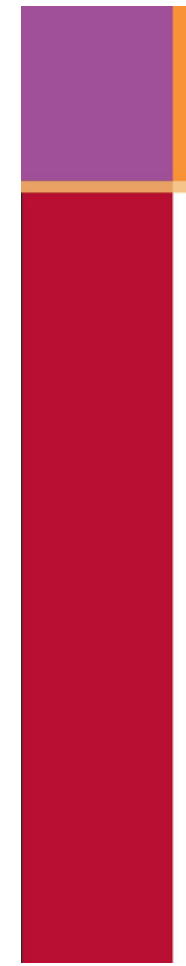

Wissenschaftspreis
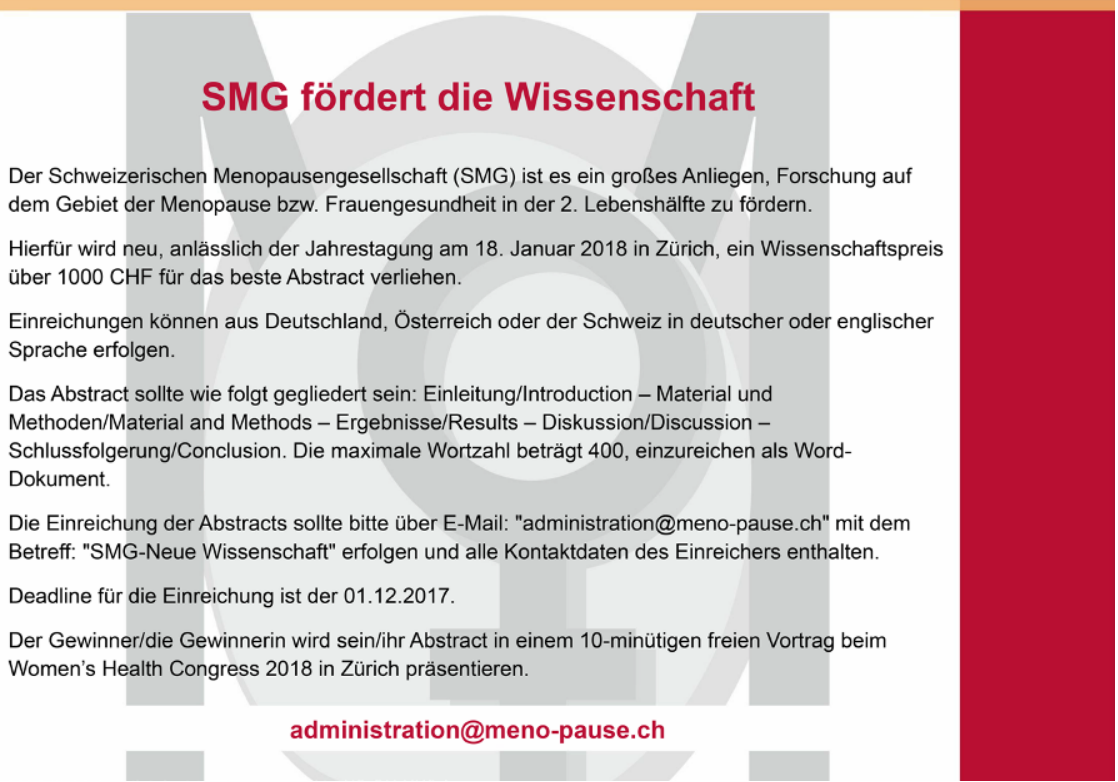

$\Delta$ Informationen, u. a. auch zu einer Mitgliedschaft in der SMG erhalten Sie von: Administration Schweizerische Menopausengesellschaft - SMG -, Anne Becker, Weißdornweg 17, 35041 Marburg/Lahn, Deutschland, Tel.: +49 (0)6420 93444, E-Mail: administration@meno-pause.ch 